\title{
First metals discovery and development the sacral component phenomenon
}

\author{
H. Haiko National Technical University of Ukraine "Kyiv Polytechnic Institute", Kyiv, Ukraine \\ V. Biletskyi National Technical University named after Yuri Kondratyuk, Poltava, Ukraine
}

ABSTRACT: This article is accentuated on the civilizational significance of the first industrial metals discovery, it reveals the prerequisites for the development of ores and the main stages of metals mastering connected with centuries-old experience of the previous mining activities of mankind. The authors suggest the hypothesis that the metallurgy was born in the depths of sustainable communities of archaic miners, which were motivated by not only utilitarian but also sacral factors. A new hypothesis is examined in comparison to the established versions of accidental discovery of metals.

Key phrases: history of mining, industrial archeology, the birth of metallurgy, primal mining communities, sacral factors, mining cults, irrational traditions

\section{THE PROBLEM AND THE STATUS OF ITS STUDY}

The phenomenon of discovering and development of the first metals has always been considered as one of the most important stages of the mankind civilizational growth. However, the continuous absence of any archaeological artifacts and the inability to use written sources (the birth of metallurgy outstripped and perhaps defined the conditions of the invention of writing) led to the hypothetical explanations for the processes of metals and metal appearance, which were based solely on the concepts and logic of their authors. This basic thesis was that the early humans randomly were witnesses of an unexpected melting of metal from ores in a home fire or forest fire and after this hint of nature they started a self-dependent metallurgical activity. At the beginning of the 20th century these hypotheses were set out in the fundamental papers (Borhers et al 1901, Kramer 1904) and the history books. From the second half of the 20th century archeology of metals begins to accumulate numerous artifacts that detailed stages of development and historical geography of metals (Chernykh 1972, Hauptmann 2000). Some archaeological works marked the frequent use of sacral factors among the primary miners (Chernykh 1972, Hauptmann 2000, Babel 2008, Kargala 2002). The authors made an attempt to explain the close relationship between the formation of sustainable mining communities, sacred worship and a birth of mining and metallurgicaltechnology in several previous works that explored the phenomenon of primitive mining activity (Gaiko 2012, Gaiko 2009, Gaiko\&Biletskyi 2013). Formed on their attempts hypothesis stands to the attention of the reader.

The purpose of this article is an analysis of possible ways of discovering the first metals, the assessment of the impact of sacral components on mining and smelting activities motivation and organization, the reasoning of the new metallurgy birth hypothesis, which answers some questions that could not be solved within the framework of other hypotheses. 
It is hard to overstate the importance of a comprehensive meaning of the metals discovery in a human civilization progress. The ore mining supplied it with fundamentally new materials that had previously unknown properties (ductility, melting) and important advantages (ability to change its shape, high toughness, operational durability). That not only effectively improved the available types of stone tools, but also created entirely new types, which opened opportunities for a technological progress. A famous American anthropologist L.H. Morgan said: "When a barbarian, moving forward step by step, discovered the native metals, began to melt them in a crucible and cast in a mold; floated native copper with tin and created bronze and ultimately, even through the greater effort of thought he invented thefurnace and pulled out iron ore - nine-tenths of the struggle for civilization was won".

Simulating ancient production processes, the researchers compared the effectiveness of using stone and copper tools. As a result, they concluded that productivity increases in case of using copper tools for felling trees -3 times, for cutting $-6-7$ times, for drilling -22 times (Semenov 1968). Metal tools had the particular importance in agriculture, where they greatly accelerated the cultivation, harvesting and construction of irrigation systems. More properties of metals were needed for the manufacturing process of weapons, including its new type - swords.

The emergence of wars, conquering tribes and peoples, the establishment of government became possible largely due to the advantages of copper weapons. One of the results of the mining and metallurgical industry formation process had become an international division of labor and an extensive development of ancient world communication system on its basis (transport of ores, metals and products of them). Search and development of new fields promoted the migration, population and development processes of distant lands. Metals also had a considerable impact on trade, as they were the first universal equivalent for commercial exchange. Civilization changes caused by the mining and metallurgical activities had a global nature and combined both technical and social components of society development (Gayko\&Biletskyi 2013).

The unique phenomenon of learning and mastering ores and their metallurgical processing is one of the highest and mysterious collective manifestations of human genius. "Why did this happen? Why do human beings do not live today as they did in the Mesolithic period?" - raised the question a researcher of primitive man $\mathrm{R}$. Braidwood. The answer on that question, which is still formed by historical science, is the cornerstone of human history.

An example of "inertia of thinking" according to the authors is the centuries-old hypothesis of the random nature of the discovery of metals, which claimed the dubious (on our opinion) idea that the birth of metallurgy is connected with observing of rare random events of copper ore melting that suddenly landed in a primitive man's fireplace. The discoverers of metal, according to this version, could be ancient hunters or ranchers who unexpectedly witnessed an accidental copper melting. Most of the modern historical reconstructions are still revealing the version of "how a shepherd became a miner".

The authors consider that this version cannot answer the basic question of R. Braidwood, why for tens of thousands years of Homo sapiens activity there were no "cases" of an accidental copper melting till Neolithic. Finding the answer on a difficult question "Why?" we have tried to study the problem from a different angle and set in the middle of the research another question, "Who?" - Who could be a discoverer of metallurgy?

The importance of this issue substantially growth considering the limited number of possible centers of metallurgy origin. Archaeological evidences of the recent decades localized the occurrence era of metallurgy (IX - VIII millennium BC) to the few centers in the eastern and central parts of Middle 
East. Later ( $\mathrm{VI}-\mathrm{V}$ millennium $\mathrm{BC}$ ) a powerful copper development center formed in the Balkans, and a thousand years later - in the South Caucasus. This "historical geography" divided researchers in monoand poly-centrists. The first ones consider that the development of copper occurred in a single center from which the mining and metallurgical knowledge was distributed ("diffused") on a broad band around the Black Sea and the Middle East. The second ones defend the hypothesis of generation of metallurgy in three or four separate centers with the following spread on the nearby and remote areas.

As we can see, only inhabitants of a several regions could participate in the initial development of metals. The presence of the rich copper ore deposits near the surface was a necessary but no a sufficient condition for their discovery.

It is also noteworthy that the termination of the ancient copper deposits operation was almost always connected not with the exhaustion of stocks, but with the resettlement (or destruction) of the population, which owned a mining and metallurgical expertise. The most typical example is the development history of a powerful Karhalynsky deposit in the Southern Urals (Kargala 2002). During III II millennium BC it was one of the richest copper mining centers in Eurasia (on the territory of size 50 by $10 \mathrm{~km}$ researchers discovered about 30 thousand mine shafts, most of which was considered as primitive mines). At the end of the II millennium BC for unknown to us reasons experienced in ore mining tribes abandoned these numerous mines. After them for three thousand years all nations that lived in these lands were no longer able to master the development of local ores, despite the fact that thousands of mine shafts basins indicated rich deposits. The complexity of this task show the sheets of Ural mining plants head G.V. de Gennin to Peter I, in which he points out that Saxon masters cannot smelt Uralian copper ores advises to invite masters from Hanover and Mansfeld, "which are able to smelt the shiver ore". Despite the participation of renowned specialists and personal control of top officials "oresmelting industry in Russia started incredibly hardand strained, it was new and very complicated business" (Pavlenko 1962).

This example shows clearly enough how difficult it was to develop the ore deposits and to get a metal even for the experts of eighteenth century and how far from scientific truth is an illusion that the copper business opening was rapidly and easily accessible for primitive people who lived in the copperrich area.

To find out who were the possible "authors" of metal discovery, we should assess the probability of random events of copper-melting and their role in the problem of development of metal. Unfortunately for "lovers of simple solutions" the melting probability of even a fusible metal copper ore in the usual fire is very low (insufficient temperature). The researchers conducted hundreds of experiments that proved impossibility of metallurgical copper ore smelting without a purposeful air blowing into the fire. In exceptional cases where the ore was caught in the kiln for firing ceramics or in a huge forest fire, the required temperature $\left(700-800^{\circ} \mathrm{C}\right)$ could be achieved, but it is not sufficient condition of metal smelting. An important factor is a presence of a special environment that demanded a comprehensive contact with charcoal.

Let us suppose that an extraordinary case brought together all the necessary conditions. In this case in the fire would have been discovered not bars or lumps of metal but only small drops of copper, inseparable from the ore, and even under a layer of ash. Even if they were found, they could not say much to an ignorant man and an attempt to replicate the melting in normal fire would probably ended as a failure. These considerations give a rise to the motivated doubts about random nature of copper ore discovering, which serves as an established version of the metal discovery. The hypothesis of successful ore searches by ignorant people also causes doubts. 
It is also important to consider that in addition to ore the native metals could be found in the mountains and valleys by anyone. Most researchers connect the primary use of the metal with the native copper. However a native cooper in a separate "stone" could be found in a huge quantity. The oldest articles thereof are small decorations (charms, beads, etc.). With high probability it can be argued that a primitive man who accidentally found a piece of copper on the earth's surface would never find the other one for the second time. With such a limited amount of metal, it is unlikely for a primal man to ponder about new production opportunities (if such considerations were possible at all for that time "inhabitants").

As you can see, the role of a "random person" in the process of metal discovering could not be decisive. Moreover, the arguments lead to the idea of targeted long-term development of metallurgicalprocesses. As L. Pasteur said - "In the fields of observation chance favors only the prepared mind."

To our opinion, there are a lot of evidences that the discovery of metals is connected with the centuries-old experience of the previous mining activities of mankind, distinguishing processes of some specific communities of archaic miners ("Hunters of Stone) in the Neolithic (and possibly earlier), accumulation and development of first knowledge about metal in these professional societies. Centuries-old experience of communities that mined and processed flint, obsidian, pyrite, raw materials for mineral paints, etc., formed a special search archaic worldview of miners that saw in stones the presence of capabilities that were sacred and hidden to a human being. At a certain stage of development of mining experience (collecting samples of native metals and ores, identifying their search attributes, styding their properties, the formation of the sacred traditions) appeared a creative idea of a new material - "malleable stone" and later "fluid stone" (metal). It has been formed and implemented by mining communities, which passed it from generation to generation for achievement of a rock art in the system of special sacral worship. The most ancient pit developments of mineral raw materials for the manufacture of paints (hematite), steel (pyrite), etc. are dated by the period of $35-40$ thousand years ago. The underground flint mining started much later (there was enough of it on the surface), but in IX - VIII millennium BC appeared the ancient flint mines that solved a range of complex technical problems already in Neolithic times.

It is important to note the scale and the focus of mining operations of Neolithic era. Almost every large deposit was opened by several thousands of mine shafts (depth $20 \mathrm{~m}$ ) with a network of horizontal workings (usually - by petal pattern). The continuous development of such deposits dates back several hundred (sometimes - thousands) of years, and there were identified tens of old mining centers (we may assume that archaeologists discovered only a small part of them), which gives a reason to believe in existence of a special sustainable community of miners, who were sedentary, were separated from the other tribes with their activity and specificity of original sacral culture.

Indirect evidences of the miners' connection to their predecessors who developed stone raw materials can be observed in similar construction techniques of Neolithic pits (the usage of "fire way" to destroy rocks) in almost identical mining tools usage, even in mandatory filling of created space. The last typical factor for flint and copper mines in the vast areas of Eurasia is especially significant, since the very labor-intensive production technologyis not life-essential (especially filling trunks), it is more a reflection of a cultural tradition. Perhaps there was a taboo for "wounding" the earth's surface, which required "curing" it by returning everything to the original state (filling cavities with wasted rock). If ore mining was carried out by people who would not have anything to do with flint mining (societies of random hunters or ranchers) this tradition would be certainly interrupted. 
In favor of the copper extraction concept as a single mining complex testified numerous archaeological excavations of ancient mines that bind ore treatment, metal melting, and even metal fabrication tools with mining activities. A placing of the oldest metallurgical plants near mines, miners settlements, mutual placing of metallurgical and mining tools, treating and smelting areas give a reason to believe that the miners and metallurgists lived for a long time the one community that dates back to the Neolithic. As an eloquent example of the mining experience continuity can serve one of the oldest human settlements - Catal-Hüyük (VIII millennium BC, southern Turkey). Close to two extinct volcanoes, it has been a center of obsidian development (volcanic glass) - the best weapon material of his time. Archaeological excavations have revealed deposits of obsidian in many buildings of the city, as well as numerous obsidian workshops. Exactly in this small village were found copper products, copper slag and scale, what confirms the possibility of the first copper smelting by the same miners, which developed stone.

Describing the first organizational and ideological factors of copper development, it should be noted that the interference into the metal's nature was perceived by a primitive man as a mystic, wonderful thing. It was filled with symbolism of sacral forces. The archaic miners felt themselves in a constant and direct contact with the other, invisible world which was to them no less apparent than a real one. There are many evidences of extremely high value of sacral and magic factors in an ancient miners' activity, which are indicating a significant impact of ancient magical cult's servants.

An objective basis for the emergence and spreading of these cults was a significantly higher (compared to other productive activities) role of uncertainties in the work results of miners, metallurgists. It was never known for certain whether the excavation (the result of hard, long and dangerous work) encounters on ore deposits, the ore quality is fine, a collapse of the mine won't happen to the worker under the ground, a flooding or fumes happen. It was unknown if the metal's smelting will be successful, if miners will be able to get a desired quantity and quality of metal.

Among the typical examples of sacral worship of miners called irrational tradition must be notified a filling the mines with a waste rock (as already mentioned); left in the Neolithic mines solar signs as mystical appeal to patrons; mining tools cult, which "helped" the successful conduct of underground works and so on. Also significant are many burial places of small ungulates in the mines and on the industrial areas (perhaps as a gratitude to the otherworldly forces for obtained mineral resources). An ancient burial miner tradition is known for burring metallurgists with working tools and a rich copper ore, which probably was a kind of "calling card" of the dead man, when he traveled to another world. Archaeologists have reconstructed some magical actions (for example, the construction of sacred labyrinth of trenches, the use of divination bones, etc.) that archaic miners performed to detect deposits for search shafts digging. Ethno-archaeologists, who studied the lifestyle of modern human societies in conditions close to their original state (the tribes of Africa, Polynesia) report that metal melting is a subject of many magical rituals: the choice of "destined by spirits" smelting time; a sanctification of melting furnace; anvil worship; numerous taboos were always respected by metallurgist and blacksmiths. Only a few men in the tribe knew the secret art of metallurgy (by R. Forbes, "the given by fire spirits power to turn stones in metal").

We believe that there was a high degree of interaction between archaic miners and archaic priests of magical cults. Presumably, this relationship was stronger among miners than in other activity fields, what leaded to more rapid formation of the ruling tribe elite (suspended - priestly caste), since the presence of minerals largely determines the richness and power of the tribe. 
It is logical to assume that the first mining and metallurgical knowledge that was considered as magical could be persisted and developed by the ancient priestly caste, which was related to mining communities, and passed them down from generation to generation. Their authority and ceremonial activities created an effective consolidation in mining community to do especially labor-intensive and dangerous underground works for numerous repetitions of complicated attempts to smelt metal (most of which did not give the desired result). We do not exclude that the invention of air blowing in the center of fire of ore, which opened up the possibility of melting steel, was associated with magical rituals of giving the ore the power, i.e. high-temperature regime could be initially invented through "ideological" and not "technological" ideas, but in an environment where both of these factors were very close.

The factor of sacred worships and their priests' activities in mining communities should be considered as one of the prerequisites for the birth of metallurgy. If the fact that the sacred practice of medieval alchemists helped discover many properties of ores, metals and their alloys and get new metallurgical technologies (Rabinovich 1979) is perceived as obvious, why we expect from the primitive communities not sacral, but purely rational way of opening of metals' secrets? Perhaps this methodological error stood in the way of accurate historical reconstruction of the beginnings of metallurgy for a long time?

From the written sources of III millennium BC is known that miners of Sumer was owned and operated directly by temple priests. This practice also took place in ancient Egypt, where existed a cult of the goddess Hathor, patroness of miners. Presumably, the projection of such relations can be reasonably widespread on the earlier period of social development. Factors of sacral worldview of a primitive man and the role of ancient cults' priests should be considered as part of the necessary conditions for the metallurgical activities establishment.

\section{CONCLUSIONS}

Prerequisites for metallurgy's genesis (according to the author's version) lied in the progressive development of mining technology of Stone Age and have been associated with the formation of a stable cultural community of "mountain people" already in the Neolithic who developed the nonmetallic minerals mining and accumulated experience for centuries. In the depths of this community began a deliberate, long-term, and associated with the cult of sacral miner's activity of metals exploration.

Factors of sacral and magical character and activities of magical cults' priests among archaic miners should be considered as a necessary condition for the birth of metallurgy, assuming that there were not only rational, but also sacral practices aimed at the discovery of the mysteries of metal (similar to the mystical practices of alchemical historic times).

It is possible that the invention of air blowing, which provided an opportunity of metal smelting process discovery, was associated with magical rituals of ore testing with the fire of huge power, i.e. high-temperature regime could be initially created through "ideological" and not "technological" motivation. 
Achievements of archaeometallurgy of recent decades add efficiently new evidences to the modern idea of the development of the Neolithic revolution; allow to separate a well-established community of miners, metallurgists and to put it next to the husbandry and pastorally communities as an important component of the Neolithic revolution.

\section{REFERENCES}

1. Babel, J. 2008. KrzemionkiOpatowskie. The earliest beginnings of modern mining. New Challenges and Visions for Mining 21st World Mining Congress.

2. Borhers, V., Vyust, V. \&Treptov, E. 1901. Mining and Metallurgy: translation from German. Industries and Technology (Encyclopedia of industrial knowledge). Association "Education": 677.

3. Chernykh, E.N. 1972. Metal - man - time. M: Nauka: 208.

4. Gaiko, G.I. 2009. The history of the development of the Earth's interior. Donetsk: East Publishing House: 292.

5. Gaiko, G.I. 2012. Birth of metallurgy - why it all happened? Technique - Youth, No 11: 16-21.

6. Gayko, G. \&Biletskyi, V. 2013. History of Mining: Textbook. Kyiv-Alchevsk Publishing House KyivMohylanska Academy of Publishers "Lado" DonSTU: 542.

7. Hauptmann, A. 2000. ZurfruhenMetallurgie des kupfers in FenanJordanien. VeroffentlichungenausDeutschenBergbau-Muzeum, No 87.

8. Kargala, T.I. 2002. Languages Slavic culture.

9. Kramer, G. 1904. The universe and humanity. The history of the study of nature and the application of its forces in the service of humanity. Association "Education": 460.

10. Pavlenko, N.I. 1962. The History of Metallurgy in Russia XVIII century. Plants and their owners. M.: Publishing USSR Academy of Sciences: 567.

11. Rabinovich, V.L. 1979. Alchemy as phenomenon of Middle Ages culture. M: Nauka: 392.

12. Semenov, S.A. 1968. The development of technics in the Stone Age. M: Nauka: 362. 